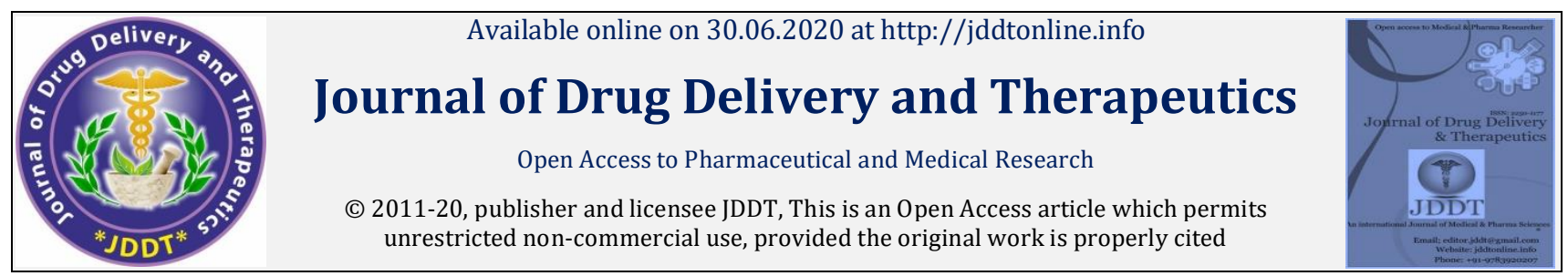

Open 1 Access

Research Article

\title{
Total Phenolic Contents, DPPH Radical Scavenging and $\beta$-Carotene Bleaching Activities of Aqueous Extract from Ammoides atlantica
}

\author{
Karima Loucif ${ }^{*}$, Hassiba Benabdallah ${ }^{1}$, Fatima Benchikh ${ }^{1}$, Soulaf Mehlous ${ }^{1}$, Chawki Ben Souici ${ }^{2}$, Smain Amira ${ }^{1}$ \\ ${ }^{1}$ Laboratory of Phytotherapy Applied to Chronic Diseases, Department of Animal Biology and Physiology, Faculty of Nature and Life Sciences, \\ University Ferhat Abbas, Setif-1, 19000, Algeria
}

${ }^{2}$ Biotechnology Research Center (CRBt), UV 03 BP E73, Nouvelle Ville Ali Mendjli, Constantine, Algeria

\begin{abstract}
Phytotherapy has known a great evolution all the world and some medicinal plants are important remedies of some diseases. Ammoides atlantica is one of the medicinal plants used in folk medicine. This study aims to estimate the total phenolics and flavonoids contents then to investigate both in vitro antioxidant activity models of aqueous extract (AqE) from Ammoides atlantica. Total polyphenol contents were determined using Folin Ciocalteu's reagent; flavonoids were quantified employing the $\mathrm{AlCl}_{3}$ Method. The in vitro antioxidant property was assessed by DPPH-scavenging radicals and lipid peroxidation assays. The results revealed that Ammoides atlantica aqueous extract presented a high total phenolic and flavonoid contents with values of $85.56 \pm 4.71 \mu \mathrm{g}$ GAE (gallic acid equivalent)/mg and $40.55 \pm 4.09 \mu \mathrm{g}$ QE (quercitin equivalent)/mg dry extract, respectively. This extract shows a good DPPH radical scavenging and $\beta$-carotene bleaching activities with an IC 50 of $107.48 \pm 5.9 \mu \mathrm{g} / \mathrm{mL}$ and $130.17 \pm 5.52 \mu \mathrm{g} / \mathrm{mL}$, respectively. This study indicates that the aqueous extract from Ammoides atlantica has potent antioxidant effects and may prove to be of latent health benefit as well as supplementary sources for natural antioxidants drugs.
\end{abstract}

Keywords: Ammoides atlantica, aqueous extract, antioxidant activity, phenolic compounds.

Article Info: Received 03 April 2020; Review Completed 08 June 2020; Accepted 21 June 2020; Available online 30 June 2020

\section{Cite this article as:}

Loucif K, Benabdallah H, Benchikh F, Mehlous S, Souici CB, Amira S, Total Phenolic Contents, DPPH Radical Scavenging and $\beta$-Carotene Bleaching Activities of Aqueous Extract from Ammoides atlantica, Journal of Drug Delivery and Therapeutics. 2020; 10(3-s):196-198 http://dx.doi.org/10.22270/jddt.v10i3-s.4151

*Address for Correspondence:

Karima Loucif, Laboratory of Phytotherapy Applied to Chronic Diseases, Department of Animal Biology and Physiology, Faculty of Nature and Life Sciences, University Ferhat Abbas, Setif-1, 19000, Algeria

\section{INTRODUCTION}

The excessive production of reactive oxygen species (ROS) overwhelming the antioxidant defense mechanisms of the cells has been shown to oxidize biological molecules and induce damage to the cell membrane, proteins, carbohydrates, and DNA. This oxidative stress is involved in several pathological situations including hypertension, heart failure and diabetes 1 . Antioxidants are compounds that can protect cells against the damage arising from unstable molecules known as ROS and free radicals 2. The use of synthetic antioxidants in the prevention of free radical damage had many toxicological side effects including carcinogenicity. For this, there is an increasing interest in the potential benefits of natural antioxidants with the potent capacity to inhibit lipid peroxidation and scavenge ROS 3 . Recently, the exploration of natural antioxidant agents from plants is an important and essential step in the evolution of effective alternative medications 4. Several polyphenols compounds are usually produced in plants and have attracted substantial recognition because of their antioxidant capabilities and free radical scavenging capabilities which are likely to be of concern to human health 5. The Ammoides atlantica (coss. et Dur.) Wolf, of the family Apiaceae, is widespread in the Mediterranean region and it is endemic in Algeria 6. Traditionally, this plant is known to be used for the therapy of fever and headache, besides its use as antidiarrheic ${ }^{7}$. Given the interest of Ammoides atlantica in folk medicine, this study aims to assess the polyphenolic contents of the aqueous extract from aerial parts of Ammoides atlantica and evaluate the in vitro antioxidant activity using DPPH radical scavenging and $\beta$-carotene bleaching assays.

\section{MATERIALS AND METHODS}

\subsection{Plant material}

\subsubsection{Plant collection and identification}

The aerial parts from Ammoides atlantica were collected from Jijel North-Eastern part of Algeria, during the flowering stage. The plant was identified and authenticated by Prof. 


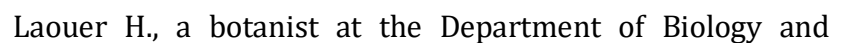
Vegetal Ecology, University of Sétif, Algeria.

\subsubsection{Extraction procedure}

$100 \mathrm{~g}$ of Ammoides atlantica powder was mixed with $1 \mathrm{~L}$ of boiling distilled water $\left(100{ }^{\circ} \mathrm{C}\right)$ and after 20 minutes, it was removed from the heat. The mixture was filtered using Wattman filter paper $\mathrm{n}^{\circ} 1$ and then dried at $45^{\circ} \mathrm{C}$ to obtain aqueous extract which was stored at $20^{\circ} \mathrm{C}$ until further analysis ${ }^{8}$.

\subsection{Determination of total phenolic and flavonoid contents}

\subsubsection{Total phenolic content}

The total phenolic content was evaluated by utilizing the reagent of Folin-Ciocalteu 9, according to a method of microplate described par Muller et al. ${ }^{10}$. Herein, $20 \mu \mathrm{l}$ of a sample (1 mg extract/1ml water) were blended with100 $\mu \mathrm{l}$ of Folin-Ciocalteu reagent (1:10) and $75 \mu \mathrm{l}$ of sodium carbonate solution $(7,5 \%)$. The microplate was incubated for two hours at room temperature in darkness. Absorbance at $765 \mathrm{~nm}$ was measured by using the microplate reader. The total phenolic content was evaluated as micrograms of gallic acid equivalents per milligrams of extract.

\subsubsection{Total flavonoids content}

Total flavonoids content was determined by the method of Topçu et al. ${ }^{11}$ with some modifications to adapt it to the microplate. Briefly, $130 \mu \mathrm{l}$ of methanol were added to $50 \mu \mathrm{l}$ of a sample (1mg extract/1 $\mathrm{ml}$ water). Subsequently, $10 \mu \mathrm{l}$ of $1 \mathrm{M}$ potassium acetate $\left(\mathrm{CH}_{3} \mathrm{COOK}\right)$ and $10 \mu \mathrm{l}$ of $10 \%$ aluminum nitrate $\left(\mathrm{Al}\left(\mathrm{NO}_{3}\right)_{3}, 9 \mathrm{H}_{2} \mathrm{O}\right)$ were added and the microplate was incubated at room temperature for 40 minutes. Absorbance was read at $415 \mathrm{~nm}$. Data were represented as micrograms of quercetin equivalents per milligrams of extract.

\subsection{Antioxidant activity assays}

\subsubsection{DPPH free radical-scavenging assay}

The free radical-scavenging capacity was determined spectrophotometrically employing the DPPH assay ${ }^{12}$. Briefly, $40 \mu \mathrm{l}$ of the sample at various concentrations was added to $160 \mu \mathrm{l}$ DPP $(0.1 \mathrm{mM})$. The reaction mixture was shaken forcefully, and the absorbance of the remaining DPPH was read at $517 \mathrm{~nm}$ after $30 \mathrm{~min}$. BHT was used as an antioxidant standard for comparison of the activity. The scavenging capability of DPPH radical was calculated using the following equation: DPPH scavenging effect $(\%)=\left[\left(\mathrm{A}_{\text {control }}-\mathrm{A}_{\text {sample }}\right) /\right.$ Acontrol $] \times 100$. The results were given as $\mathrm{IC}_{50}$ values $(\mu \mathrm{g} / \mathrm{ml})$ corresponding to the concentration of $50 \%$ inhibition.

\subsection{2. $\beta$-Carotene/linoleic acid assay}

The $\beta$-carotene bleaching activity was evaluated using the $\beta$ carotene-linoleic acid system described by Marco 13 . Thus, a solution of $\beta$-carotene $(0.5 \mathrm{mg})$ in $1 \mathrm{ml}$ of chloroform is combined with $25 \mu \mathrm{l}$ of linoleic acid and $200 \mu \mathrm{l}$ of Tween 40 . After evaporation in vacuo of the chloroform, $50 \mathrm{ml}$ of hydrogen peroxide $\left(\mathrm{H}_{2} \mathrm{O}_{2}\right)$ is added under vigorous agitation. The absorbance of the solution is then adjusted to 0.8-0.9 $\mathrm{nm}$. Amounts of $160 \mu \mathrm{l}$ of this solution are added to $40 \mu \mathrm{l}$ of a sample at different concentrations. The absorbance was measured at $470 \mathrm{~nm}$, using a 96-well microplate reader. The emulsion system was incubated for $2 \mathrm{~h}$ at $50^{\circ} \mathrm{C}$. BHT was used as a reference. The bleaching rate (R) was assessed as follows: $\mathrm{R}=(\ln \mathrm{c} / \mathrm{d}) / \mathrm{t}$. Where: $\mathrm{c}=$ absorbance at time zero, $\mathrm{d}=$ absorbance at time $120 \mathrm{~min}(\mathrm{t})$ and $\mathrm{ln}=$ natural log. The antioxidant activity (AA) was calculated in terms of percent of inhibition relative to the control, using the following equation: $\mathrm{AA}(\%)=\left[\left(\mathrm{R}_{\text {Control }}-\mathrm{R}_{\text {Sample }}\right) / \mathrm{R}_{\text {Control }}\right] \times 100$.

\subsection{Statistical analysis}

Results are represented as the mean \pm standard deviation (SD) and all measurements were conducted in three determinations $(n=3)$. The statistical interpretation was directed by the help of a one-way analysis of variance (ANOVA) for significance with the aid of Graph Pad Prism 7.00. differences were examined significant at $p \leq 0.05$.

\section{RESULTS}

\subsection{Total phenolics and flavonoids contents}

The results showed that the Ammoides atlantica aqueous extract (AqE) was rich in polyphenols and flavonoids $(141.74 \pm 0.44 \mu \mathrm{g} \mathrm{GAE} / \mathrm{mg}$ dry extract and $61.87 \pm 6.7 \mu \mathrm{g}$ $\mathrm{QE} / \mathrm{mg}$ dry extract, respectively) as shown in Table 1.

Table 1: Total polyphenols and flavonoids content of Ammoides atlantica aqueous extract. AqE: aqueous extract, (a): $\mu \mathrm{g}$ GAE/mg and (b): $\mu \mathrm{g} \mathrm{QE} / \mathrm{mg}$.

\begin{tabular}{|c|c|c|}
\hline Extract & Total phenolic content(a) & Total flavonoid content(b) \\
\hline AqE & $141.74 \pm 0.44$ & $61.87 \pm 6.7$ \\
\hline
\end{tabular}

\subsection{Antioxidant activities}

The $\mathrm{IC}_{50}$ values of DPPH radical scavenging and $\beta$-carotene bleaching activities from Ammoides atlantica aqueous extract (AqE) are presented in Table 2. The results revealed that the
AqE presented a good scavenging activity against DPPH, with an $\mathrm{IC}_{50}$ of $204.22 \pm 12.16 \mu \mathrm{g} / \mathrm{mL}$. As well, AqE displays a strong $\beta$-carotene bleaching activity with an $\mathrm{IC}_{50}$ of $112.45 \pm 6.66 \mu \mathrm{g} / \mathrm{mL}$. This suggests a significant antioxidant activity from AqE.

Table 2 : Antioxidant activities of Ammoides atlantica aqueous extract (AqE). ${ }^{* * * *} \mathrm{p}<0.0001$ compared to correspondent standards. AqE: aqueous extract, DPPH: 2,2-diphenyl-1-picrylhydrazyl, BHA: butylated hydroxyanisole and BHT: butylated hydroxytoluene.

\begin{tabular}{|c|c|c|}
\hline \multirow{2}{*}{ Extract/ standard } & \multicolumn{2}{|c|}{$\mathrm{IC}_{50}(\mu \mathrm{g} / \mathrm{mL})$} \\
\cline { 2 - 3 } & DPPH scavenging activity & $\beta$-carotene bleaching activity \\
\hline AqE & $204.22 \pm 12.16^{* * * *}$ & $112.45 \pm 6.66^{* * * *}$ \\
\hline BHA & $5.73 \pm 0.41$ & $0.90 \pm 0.02$ \\
\hline BHT & $22.32+1.19$ & $1.05+0.01$ \\
\hline
\end{tabular}




\section{DISCUSSION}

Our results showed that the Ammoides atlantica aqueous extract (AqE) was a good source of polyphenol and flavonoid compounds. These results agree with the findings of 14 Antioxidant capacity from AqE was assessed by DPPHscavenging radicals and lipid peroxidation assays. In DPPH radical scavenging test, A freshly formulated solution of DPPH shows a dark purple color with maximum absorption at $517 \mathrm{~nm}$. The purple hue usually fades/disappears in the medium contains antioxidants, Thus, antioxidant molecules can neutralize DPPH-free radicals; by provide hydrogen atoms or donate electrons and convert them to a colorless/bleached substance (2,2-diphenyl-1 hydrazine or equivalent hydrazine substituted), resulting in a decrease in absorption at the $517 \mathrm{~nm}$ level. The more rapidly absorbance falls, the more efficient the extract's antioxidant function in terms of atomic hydrogen-donating ability 15 . The results revealed that the AqE presented a good DPPH radical scavenging potential. This could be attributed to polyphenols and flavonoids 16 . The ability of Ammoides atlantica aqueous extract (AqE) to inhibit lipid peroxidation was tested by the $\beta$-carotene bleaching method. $\beta$-carotene in the absence of the antioxidant undergoes a rapid decolorization since the free linoleic acid radical attacks the $\beta$-carotene, which loses the double bonds and, consequently, its orange color ${ }^{17}$. The presence of a phenolic antioxidant can hinder the extent of bcarotene destruction by "neutralizing" the linoleate free radical (utilizing its redox potential) and any other free radicals formed within the system. Hence, this test can be used to examine the antioxidant potential of Ammoides atlantica AqE 18. The results showed that AqE was able to inhibit lipid peroxidation. These antioxidant activities could be attributed to the richness of this extract in polyphenols and flavonoids. In fact, the literature showed that a good correlation was found between antioxidant activity and the content of polyphenols and flavonoids 19,20 . Our results are in accordance with those of 14,21 , who demonstrated that the Ammoides atlantica extracts have potent antioxidant capacities.

\section{CONCLUSION}

The aqueous extract of Ammoides atlantica exhibited good antiradical activities toward 2,2'- diphenyl-1-picrylhydrazyl (DPPH) and acting as inhibiting lipid peroxidation. This may explain the medicinal use of this plant in folk medicine. These results suggest that AqE of Ammoides atlantica might be promising for the treatment or prevention of many diseases associated with oxidative damage. Further researches needed to identify and isolate the active principles present in this extract which could be useful for pharmaceutical purposes.

\section{ACKNOWLEDGMENTS}

This work was supported by the Algerian Ministry of Higher Education and Scientific Research (MESRS). We express our gratitude to these organizations. Authors would like also to thank Prof. Hocine LAOUER (Laboratory of Valorization of Natural Biological Resources, University of Sétif1, Algeria) for the identification of the plant material.

\section{REFERENCES}

[1] Gönenç A, Hacışevki A, Tavil Y, Çengel A, Torun M, Oxidative stress in patients with essential hypertension: a comparison of dippers and non-dippers, Eur J Intern Med, 2013; 24:139-144.

[2] Saxena M, Saxena J, Pradhan A, Flavonoids and phenolic acids as antioxidants in plants and human health, Int J Pharm Sci Rev Res, 2012; 16(2):130-4.
[3] Gonçalves S, Gomes D, Costa P, Romano A, The phenolic content and antioxidant activity of infusions from Mediterranean medicinal plants, Ind Crops Prod, 2013; 43:465-471.

[4] Singh M, Pandey N, Agnihotri V, Singh KK, Pandey A, Antioxidant, antimicrobial activity and bioactive compounds of Bergenia ciliata Sternb.: A valuable medicinal herb of Sikkim Himalaya, J Tradit Complement Med, 2017; 7:152-157.

[5] Pereira DM, Patrícia V, Pereira JA, Andrade PB, Phenolics: From Chemistry to Biology, Molecules, 2009; 14:2202-2211.

[6] Quezel P, Santa S. Nouvelle flore de l'Algérie et des régions désertiques méridionales. Centre National de la Recherche Scientifique, Paris; 1963.

[7] Bellakhdar J. La pharmacopée marocaine traditionnelle. Médecine arabe ancienne et savoirs populaires. Ibiss Press, Paris ; 1997.

[8] Ferreira A, Proença C, Serralheiro ML, and Araújo ME, The in vitro screening for acetylcholinesterase inhibition and antioxidant activity of medicinal plants from Portugal, J.Ethnopharmacol, 2006; 108:31-37.

[9] Singleton VL, Rossi JA, Colorimetry of total phenolics with phosphomolybdic-phosphotungstic acid reagent, Am J Enol Vitic, 1965; 16:144-58.

[10] Muller L, Gnoyke S, Popken AM, Bohm V, Antioxidant capacity and related parameters of different fruit formulations, LWTFood Sci Technol, 2010; 43(6): 992-9.

[11] Topçu G, Ay A, Bilici A, Sarıkürkcü C, Öztürk M, Ulubelen A, A new flavone from antioxidant extracts of Pistacia terebinthus, Food Chem, 2007; 103(3):816-22.

[12] Blois MS, Antioxidants determination by the use of a stable free radical, Nature, 1958; 26:1199-200.

[13] Marco GJ, A rapid method for evaluation of antioxidants, J Am Oil Chem Soc, 1968; 45:594-8.

[14] Benteldioune M, Boudiar T, Bakhouche A, Contreras MDM, Lozano-Sanchez JL, Bensouici C, Kabouche Z, Segura-CarreteroA, Antioxidant activity and characterization of flavonoids and phenolic acids of Ammoides atlantica by RP-UHPLC-ESI-QTOFMSn, Natural Product Research, 2019; 1-5.

[15] Yamaguchi T, Takamura H, Matoba T, Terao J, HPLC method for evaluation of the free radical-scavenging activity of foods by using 1,1-diphenyl-2-picrylhydrazyl, Bioscience, Biotechnology, and Biochemistry, 1998; 62:1201-1204.

[16] Miliauskas G, Venskutonis PR, Van-Beck TA, Screening of radical scavenging of some medicinal and aromatic plant extracts, Food Chem, 2004 ; 85:231-237.

[17] Benchikh F, Benabdallah H, Amira S, The Evaluation of Antioxidant Capacity of Different Fractions of Myrtus communis L. Leave, Annual Research \& Review in Biology, 2018; 22(5):114.

[18] Amarowicza R, Peggb RB, Rahimi-Moghaddamc P, Barld B, Weilc JA, Free-radical scavenging capacity and antioxidant activity of selected plant species from the Canadian prairies, Food Chemistry, 2004; 84:551-562.

[19] Conforti F, Sosa S, Marrelli M, Menichin F, Statti GA, Uzunov D, TubaroA, In vivo anti-inflammatory and in vitro antioxidant activities of Mediterranean dietary plants, J. Ethnopharmacol, 2008; 116:144-151.

[20] Li HB, Wong CC, Cheng KW, Chen F, Antioxidant properties in vitro and total phenolic contents in methanol extracts from medicinal plants, LWT - Food Sci. Technol (Leben smittelWissenschaft -Technol.), 2008; 41(3):385-390.

[21] Ababsa ZEA, Benkiki N, Derouiche MT, Louaar S, Medjroubi K, Akka IS, In vivo anti-inflammatory activity of the species: Ammoides atlantica of Apiaceaefamily, Der Pharmacia Lettre, 2011; 3(6):46-48. 